\title{
Fractal Model for Simulation of Membrane Deposition and Growth in Microfiltration Membranes
}

\author{
Honglei Zhang ${ }^{1,2, a}$, Yan $\mathrm{Shi}^{2,3, \mathrm{~b}^{*}}$, Danyu $\mathrm{Xu}^{2,3}$ and Ying Hou ${ }^{3}$ \\ ${ }^{1}$ College of Management and Economics, Tianjin University, 92 Weijin Road, Nankai District, \\ Tianjin, P.R. China 300072 \\ ${ }^{2}$ Tianjin Academy of Environmental Science, 17 Fukang Road, Nankai District, \\ Tianjin, P.R. China 300191 \\ ${ }^{3}$ Tianjin United Environmental Engineering Design Company Limited, 17 Fukang Road, \\ Nankai District, Tianjin, P.R. China 300191 \\ a452959384@qq.com, bshiyan800712@126.com
}

\begin{abstract}
Keywords: DLA model, Fractal dimension, Micro-PIV, Quantum dot, Membrane deposition and growth

Abstract. A membrane deposition and growth model based on fractal theory was developed. This model can dynamically describe the fouling process on the outer surface of membranes. Using this model to change boundary conditions and initial particle production probabilities, the process of membrane deposition and growth was simulated under different conditions. Micro-PIV technology was applied in a membrane fouling observation experiment. The morphology of membrane deposits was determined using quantum dot fluorescent tracers, and the surrounding flow field was simultaneously observed and analyzed. The fractal dimensions obtained were as expected. Findings indicate that membrane deposition and growth model developed in this work describes real phenomena accurately. The model was used to simulate the impact of flow field and suspended solid concentration on dynamic variations in membrane deposition.
\end{abstract}

\section{Introduction}

Membrane filtration has been successfully applied to wastewater treatment for over a decade. Today, however, membrane fouling continues to be the major problem encountered in membrane processes [1-3]. Numerous procedures have been proposed to characterize and minimize fouling [4-6], and a number of models have been used to quantitatively analysis the formation process of pollution and interfacial interactions between solid particles, humic acids, and protein. These models include the flux model, DLVO (Dejarguin-Landau-Verwey-Overbeek) theory, computational fluid dynamics (CFD), etc [7-10]. However, accurately revealing the dynamic growth behavior of membrane deposits remains a challenge to many scientists. Membrane fouling is a continuous and long-term process. It need high technical requirement to accuracy and sensitivity track the whole process of deposits accumulation on membrane surface. Thus, previous testing technologies, for example, scanning electron microscopy and indirect estimation from daily operation parameters, among others, can only provide intermittent or "phenomenological" information [11,12]. To solve the current problems at least partially, this work aims to develop a model of membrane deposition and growth based on fractal theory. Micro-PIV technology was applied for experimental verification. Using the proposed model to change boundary conditions and initial particle production probabilities, the process of membrane deposition and growth in CMF (continuous micro-filtration) was simulated under different conditions. Results not only provide important information revealing dynamic variations in membrane deposition but also serve as a reference for future research on the similar membrane reactors. 


\section{Materials and Methods}

\section{Experimental Apparatus.}

Membrane Preparation. In this study, a cross-flow microfiltration system was used. This system was made up primarily of a cross-flow cell, a feed tank, a pump, and a pressure gauge. The feed was pumped from the feed tank toward the cell. The inlet pressure and cross-flow velocity were controlled by by-pass and outlet valves, respectively. The cell was made of Perspex. Polyvinylidenefluoride (PVDF) commercial membrane (GVWP) from Millipore was employed in this study. The average pore diameter of the $120 \mu \mathrm{m}$-thick membrane was about $0.22 \mu \mathrm{m}$ and its porosity was $65 \%$. Table 1 shows the components of water used in the experiments while Table 2 shows the relevant operating conditions.

Table 1 Operating conditions for the current experiments

\begin{tabular}{ccc}
\hline $\begin{array}{c}\text { Operation } \\
\text { conditions }\end{array}$ & $\begin{array}{c}\text { Pressure } \\
{[\mathrm{kPa}]}\end{array}$ & $\begin{array}{c}\text { Suspended solids } \\
\text { concentration } \\
{[\mathrm{mg} / \mathrm{L}]}\end{array}$ \\
\hline Effect of pressure & 100 & 100 \\
& 200 & 100 \\
Effect of & 300 & 100 \\
concentration & 100 & 150 \\
& 100 & 200 \\
\hline
\end{tabular}

Table 2 Water quality components in the experiments

\begin{tabular}{cc} 
Component & Mass ratio \\
Glucose & 30 \\
Calcium sulfate $\left(\mathrm{CaSO}_{4}\right)$ & 18 \\
Potassium dihydrogen phosphate $\left(\mathrm{KH}_{2} \mathrm{PO}_{4}\right)$ & 8 \\
Sodium chloride $(\mathrm{NaCl})$ & 14 \\
Ferrous sulfate $(\mathrm{FeSO})$ & 11 \\
Magnesium chloride $\left(\mathrm{MgCl}_{2}\right)$ & 10 \\
Ammonium chloride $\left(\mathrm{NH}_{4} \mathrm{Cl}\right)$ & 9 \\
\hline
\end{tabular}

Micro Particle Image Velocimetry. Image testing methods have been gradually used in membrane research [13]. Because micro-PIV (micro particle image velocimetry) technology is used as an optical detection method, interferences from the mechanical probe on flow field distributions can be avoided and the distribution of the whole flow field can be obtained. This technology has been used in studies of MEMS[14], aerospace[15], biomedicine[16], and other research fields. Fig. 1 illustrates the general setup of the experiment. The setup was composed of an image acquisition system, a high-speed CCD camera, a synchronous controller, a laser device, and a microscope objective. Considering actual measuring requirements, the laser used was a double-pulse YAG laser (service frequency: $15 \mathrm{~Hz}$, maximum pulse energy: $250 \mathrm{~mJ}$; NewWave Inc., USA). The CCD camera had a resolution of $1600 \times 1200$ pixels (PCO-1600, Cook Inc., Germany). The microscopic objective added filtering device only allows the wavelength of $610 \mathrm{~nm}$ and red light through a relay mirror 
(Apo $\times 10$, Mitutoyo Inc., Japan).The flow-tracing particles used in this study were Quantum Nanospheres (QNs), created by conjugating fluorescent Quantum Dots (QDs) to polystyrene beads. The effective hydrodynamic diameter of the nanospheres was about $70 \mathrm{~nm}$. The fluorescent QNs had a large Stokes' shift and were impervious to photobleaching. The QDs were water-soluble (CdSe)ZnS with a diameter of about $6 \mathrm{~nm}[17,18]$.

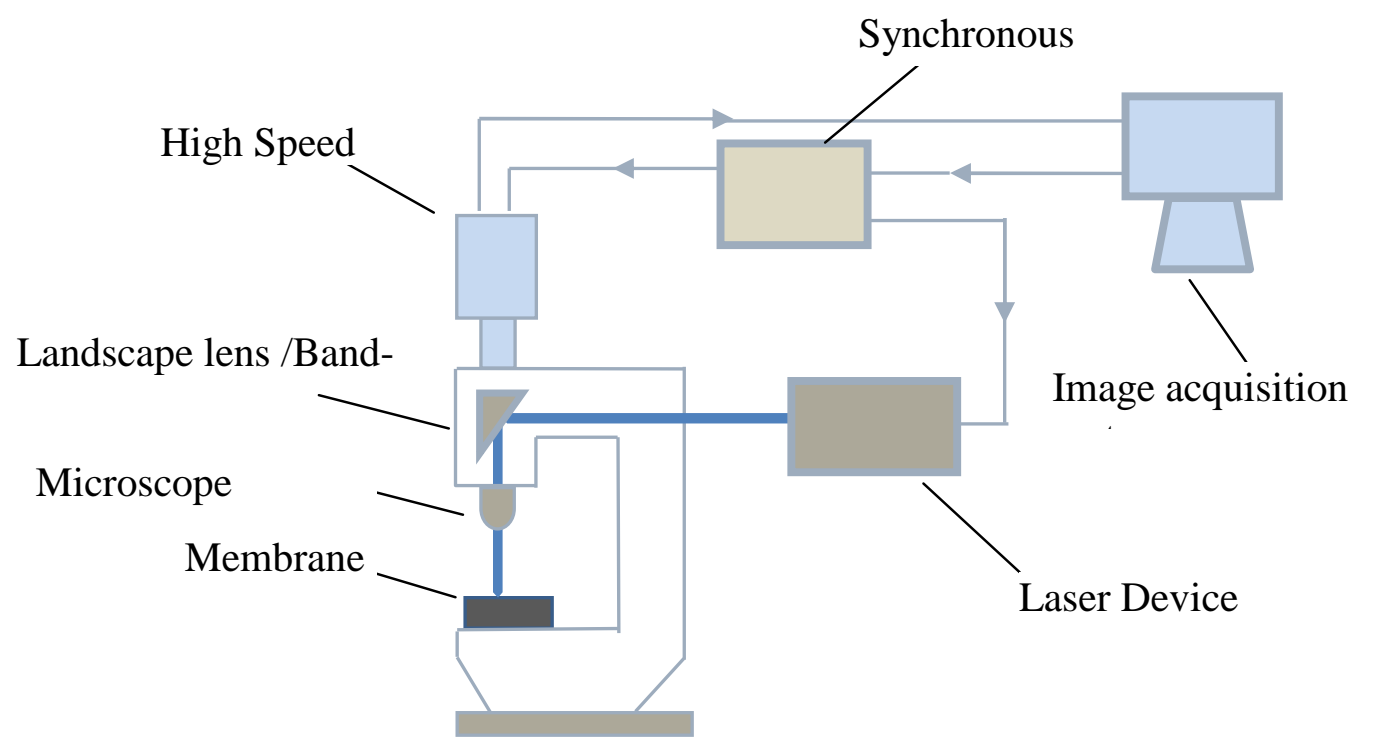

Fig. 1. Experimental configuration for micro-PIV measurement

Experimental Method. Membrane deposition is a dynamic equilibrium process, and short-term changes in deposits on the membrane surface are difficult to describe. The cross-flow microfiltration system was run under different experimental conditions and the same flux was maintained for about 3 weeks. Membrane deposition was observed in real time by a CCD camera. Fig. 2 illustrates the process of membrane deposition under experimental conditions of pressure $=100 \mathrm{kPa}$ and $\mathrm{SS}=100$ $\mathrm{mg} / \mathrm{L}$.
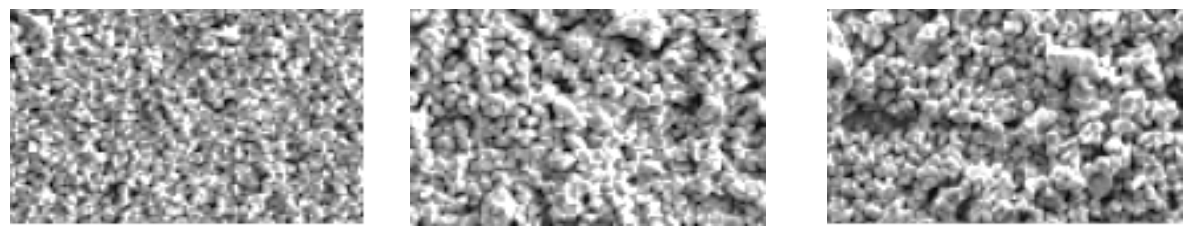

Fig. 2 Evolution of membrane deposits under condition of pressure $=100 \mathrm{kPa}, \mathrm{SS}=100$

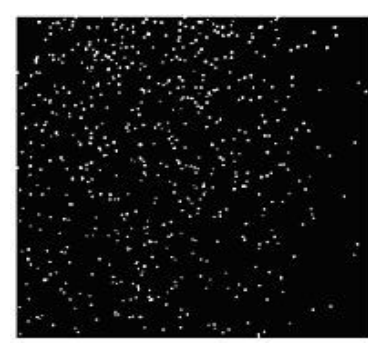

First frame

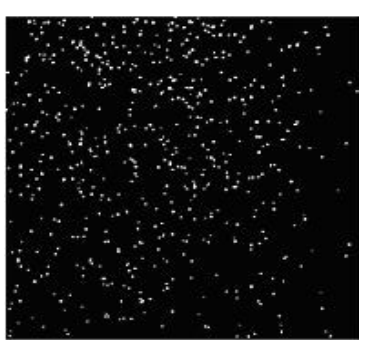

Second frame

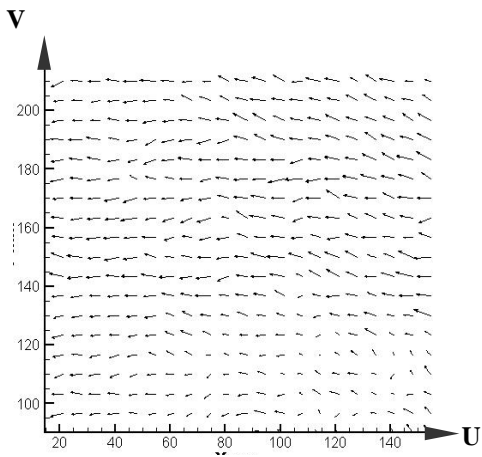

Fig.3 The original particle images and its vector 
In this study, the Micro-PIV was applied in the test flow field of the microfiltration system. First, spread good-following fluorescent tracer particles into the observation of fluid. Second, the tracer particles were excited by laser illumination, and two consecutive exposure images (time interval $\Delta t$ ) were record by a CCD camera and stored in a computer. Finally, the images were processed, and the displacement of tracer particles $(\Delta s)$ was calculated by the correlation processing technique. The complete flow field velocity vector was further obtained. Fig. 3 shows the original particle flow images and their vector distribution.

\section{Mathematical Model}

Modeling. The diffusion limited aggregation model (DLA) is one of the most important growth models in fractal theory. Through kinematic and dynamic equations, the model can generate the scale invariance of self-similar fractal structures [19]. In a previous experimental study, initial membrane fouling was found to occur easily on outer surfaces. As fouling increased, membrane fouling showed branched crystal. This process reflects self-similarity and fractal characteristics. Considering the characteristics of outer surface fouling on the micro-filtration membrane, the DLA model was applied to simulate the growth of membrane deposits in this study. To do so, the following steps were performed:

(1) A square lattice is generated for the initial membrane fouling growth space.

(2) Some seeds representing trapped particles are generated on the bottom edge of the square because initial membrane deposits often formation and grow from particles trapped on the membrane surface as seeds.

(3) Particles are randomly generated in the square space to represent solid pollutants separated by a membrane. The "particles" walk randomly in accordance with the rules of the DLA growth model.

(4) To judge whether the particle walk randomly to meet other around particles. If it is, they will be adhered together. If not then continue step 3.

(5) If the randomly walk of the particle outwards over a certain range, make it stop, and then let the next particle start.

(6) To complete the cycle times of the set, the program was running over.

Simulation of Model. Using the model above, membrane deposition and growth in a microfiltration membrane were simulated in two section directions (i.e., $\mathrm{X}-\mathrm{Y}$ and $\mathrm{X}-\mathrm{Z}$ ) under experimental conditions. Figs. 4 and 5 show the growth process of membrane deposits at different periods (experimental conditions: pressure $=100 \mathrm{kPa}$; SS: $100 \mathrm{mg} / \mathrm{L}$ ).

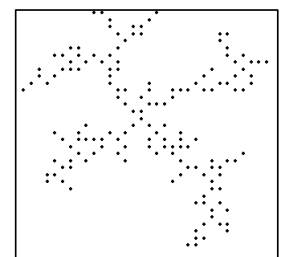

First week

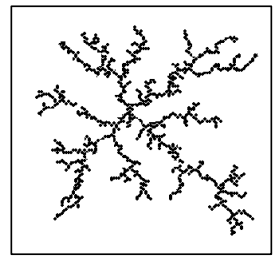

Second week

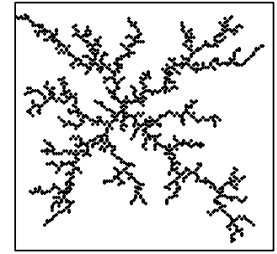

Third week

Fig. 4 The simulation result of membrane deposits fractal evolution in X-Y section

Horizontal velocity: $1.97 \mathrm{~mm} / \mathrm{s}$

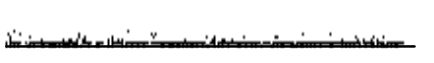

First week
2010

Second week

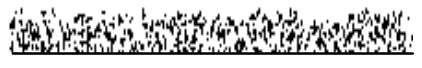

Third week

Fig. 5 The simulation result of membrane deposits fractal evolution in X-Z 
The simulation and experimental image of membrane deposition have pleasurable agreement with morphological trend (Figs. 2, 4, and 5).On the one hand, the crystal nucleus, which induces membrane deposition, constantly grows with time (Fig. 2). On the basis of the crystal nucleus, New and small branches gradually appear from the crystal. When the experimental research was carried out for a certain period of time, membrane deposits increasingly demonstrated self-similarity and fractal characteristics. On the other hand, as shown in Fig. 4 and Fig. 5, the molecular cluster configuration becomes more and more complex as the simulation time increases, which indicates increasingly serious membrane pollution. Meanwhile, the method used cycle number to represent the runtime of membrane fouling was reasonable.

Model Validation. Fractal dimensions were used to evaluate the fractal characteristics of the images above [20]. In this study, the box-counting method was used to solve fractal dimensions. The solution program was developed on the Matlab6.0 platform. The experimental $\left(\mathrm{D}_{\mathrm{f} 1}\right)$ and simulated $\left(\mathrm{D}_{\mathrm{f} 2}\right)$ fractal dimensions are listed in Table 3.

Table 3 Analytical results of experimental and simulated membrane deposition

\begin{tabular}{|c|c|c|c|c|c|c|}
\hline \multicolumn{2}{|c|}{ Operating conditions } & \multicolumn{2}{|l|}{ Results } & \multicolumn{2}{|c|}{ Simulation results } & \multirow{2}{*}{$\begin{array}{l}\text { Relative error } \\
\qquad(\%)\end{array}$} \\
\hline Pressure $(\mathrm{kPa})$ & $\mathrm{SS}(\mathrm{mg} / \mathrm{L})$ & Run time (week) & $\mathrm{D}_{\mathrm{f} 1}$ & Run number & $\mathrm{D}_{\mathrm{f} 2}$ & \\
\hline & & 1 & 1.05 & 5000 & 1.01 & 3.81 \\
\hline \multirow[t]{3}{*}{100} & 100 & 2 & 1.32 & 10000 & 1.27 & -3.79 \\
\hline & & 3 & 1.51 & 15000 & 1.48 & -1.99 \\
\hline & & 1 & 0.98 & 5000 & 0.95 & -3.06 \\
\hline \multirow[t]{3}{*}{200} & 100 & 2 & 1.28 & 10000 & 1.26 & -1.56 \\
\hline & & 3 & 1.49 & 15000 & 1.42 & -4.70 \\
\hline & & 1 & 0.92 & 5000 & 0.97 & 5.43 \\
\hline \multirow[t]{3}{*}{300} & 100 & 2 & 1.19 & 10000 & 1.15 & -3.36 \\
\hline & & 3 & 1.39 & 15000 & 1.33 & -4.32 \\
\hline & & 1 & 1.22 & 5000 & 1.25 & 2.46 \\
\hline \multirow[t]{3}{*}{100} & 200 & 2 & 1.36 & 10000 & 1.31 & -3.68 \\
\hline & & 3 & 1.57 & 15000 & 1.49 & -5.10 \\
\hline & & 1 & 1.34 & 5000 & 1.36 & 1.49 \\
\hline \multirow[t]{3}{*}{100} & 400 & 2 & 1.45 & 10000 & 1.48 & 2.07 \\
\hline & & 3 & 1.63 & 15000 & 1.66 & 1.84 \\
\hline & & 1 & 1.39 & 5000 & 1.41 & 1.44 \\
\hline \multirow[t]{2}{*}{100} & 600 & 2 & 1.61 & 10000 & 1.63 & 1.24 \\
\hline & & 3 & 1.82 & 15000 & 1.85 & 1.65 \\
\hline
\end{tabular}

Note: Due to restrictions of shielding effects in this model, the boundary enrichment phenomenon was often observed when the iteration number exceeded 15000. The iteration times listed in the Table 3 take 15000 times as the upper boundary.

Similarities in morphology may be illustrated by similarities in fractal dimensions obtained through experimentation and simulation. Although the process of membrane deposits formation and growth was random in the experiment or simulation, the variable trend of fractal dimension was consistent (see Table.3). As the running or simulation time increased, fractal dimensions increased gradually, and a positive correlation was initially observed. The relative error range of fractal dimensions between the experiment and simulation ranged from $-5.1 \%$ to $5.43 \%$. This result indicates that the proposed model of membrane deposition and growth describes real phenomena accurately. 


\section{Result and Discussion}

Impact of Superficial Inlet Velocity on Membrane Deposition and Growth. To describe membrane deposition in the microfiltration system under different pressure conditions accurately, a certain initial velocity is given to the "particles" of the DLA model at the beginning of simulation. The initial velocity was determined by the micro-PIV system through experimentation. Inlet pressure and horizontal velocity showed a positive relation. The higher the pressure given, the faster the velocity observed. Under identical conditions, such as in the simulation results shown in Fig. 8, the particle layer increased with increasing time. Under different conditions, particles become more difficult to adsorb as horizontal velocity increased (Figs. 5-7). These results suggest that flushing the membrane surface inhibits membrane pollution.

Horizontal velocity: $3.21 \mathrm{~mm} / \mathrm{s}$

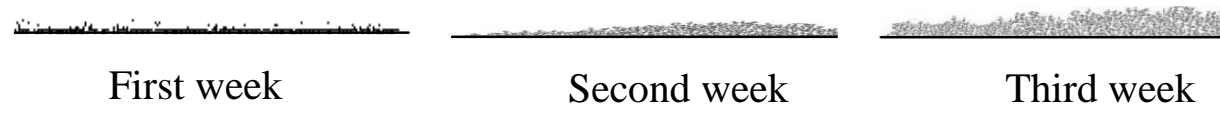

Fig. 6 Simulation results (image of the $X-Z$ section) under pressure $=100 \mathrm{kPa}, \mathrm{SS}=100 \mathrm{mg} / \mathrm{L}$

Horizontal velocity: $5.71 \mathrm{~mm} / \mathrm{s}$

First week

Second week

Third week

Fig. 7 Simulation results (image of the $X-Z$ section) under pressure $=200 \mathrm{kPa}, \mathrm{SS}=100 \mathrm{mg} / \mathrm{L}$

Impact of Contaminant Concentration on Membrane Deposition and Growth. Seeds were set to different densities to represent the concentrations of suspension particles. Under the same initial pressure and velocity, seed densities induced particle absorption easily (Figs.8-10). A direct relationship between membrane deposition speed and MLSS concentration was observed. High initial particle densities promoted accumulation of membrane deposits. Membrane fouling particles agglomerate easily at high initial particle densities, and membrane deposition speed and SS concentration showed a positive relation.

Horizontal velocity: $1.97 \mathrm{~mm} / \mathrm{s}$

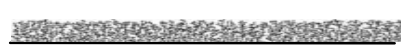

First week

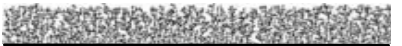

Second week

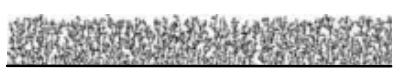

Third

Fig. 8 Simulation results (image of the X-Z section) under pressure $=200 \mathrm{kPa} S S=150 \mathrm{mg} / \mathrm{L}$

Horizontal velocity: $1.97 \mathrm{~mm} / \mathrm{s}$

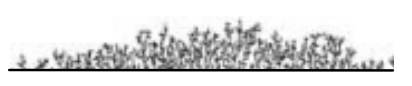

First week

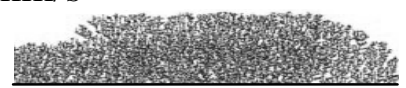

Second week

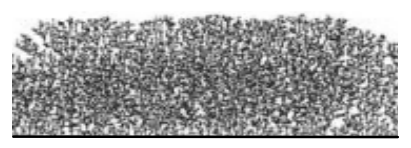

Third

Fig.9 Simulation results (image of the X-Z section) under pressure $=100 \mathrm{kPa} S S=150 \mathrm{mg} / \mathrm{L}$ 


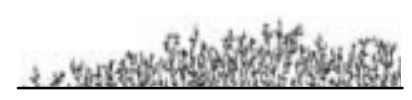

First week

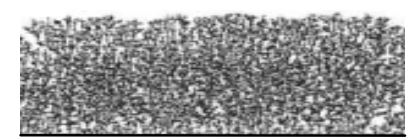

Second week

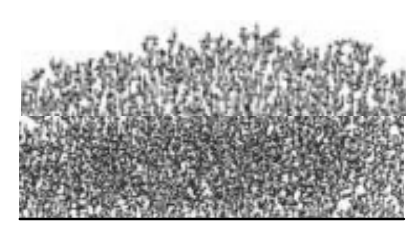

Third week

Fig.10 Simulation results (image of the $X-Z$ section) under pressure $=100 \mathrm{kPa}, \mathrm{SS}=250 \mathrm{mg} / \mathrm{L}$

\section{Conclusions}

(1) A membrane deposition and growth model based on fractal theory was developed. This model can dynamically describe the fouling process on the outer surface of membranes. Using this model to change boundary conditions and initial particle production probabilities, the process of membrane deposition and growth was simulated under different conditions.

(2) Micro-PIV technology was applied in a membrane fouling observation experiment. The morphology of membrane deposits was determined using QD fluorescent tracers, and the surrounding flow field was simultaneously observed and analyzed.

(3) In this study, the box-counting method was used to solve the fractal dimensions obtained through simulation and experimental images. The fractal dimensions obtained were as expected. Findings indicate that membrane deposition and growth model developed in this work describes real phenomena accurately.

(4) The model was used to simulate the impact of flow field and SS concentration on dynamic variations in membrane deposition. Results showed that flow field is an important factor determining membrane deposition in CMF. Cross-flushing of the membrane surface inhibited membrane pollution. A direct relationship between membrane deposition speed and MLSS concentration was further observed.

\section{Acknowledgements}

This work was financially supported by the National Natural Science Foundation of China (Grant $51208358,51178311)$. We appreciate the critical comments of the anonymous reviewers.

\section{References}

[1] Kang I J, Yoon S H, Lee C H. Comparison of the filtration characteristics of organic and inorganic membranes in a membrane coupled anaerobic bioreactor[J]. Water Research, 2002,36: 1803-1813.

[2] Chan C C, Berube P R, Hall E R, et al., Relationship between types of surface shear stress profiles and membrane fouling[J].Water Research,2011,45:6403-6416.

[3] Choi J S, Hwang T M, Lee S, et al. A systematic approach to determine the fouling index for a RO/NF membrane process[J]. Desalination, 2009,238:117-127.

[4] Charfia A, Yanga Y, Harmand J, et al. Soluble microbial products and suspended solids influence in membrane fouling dynamics and interest of punctual relaxation and/or backwashing[J]. Journal of Membrane Science,2015,2(475):156-166.

[5] Meijia Z, Baoqiang L, Xiaoling Z, et al. Effects of hydrophilicity/hydrophobicity of membrane on membrane fouling in a submerged membrane bioreactor[J]. Bioresource Technology, 2015, 175:59-67.

[6] Wang C, Chen W N, Hu Q Y, et al. Dynamic fouling behavior and cake layer structure changes in nonwoven membrane bioreactor for bath wastewater treatment[J]. Chemical Engineering Journal, 2015, 264(15): 462-469. 
[7] William J.T, John Chew, Michael R B. The application of fluid dynamic gauging in characterising cake deposition during the cross-flow microfiltration of a yeast suspension[J]. Journal of Membrane Science, 2012, 405: 113-122.

[8] Yao S D, Gao X Y, Guo B H, et al. Reverse Osmosis Membrane Fouling by Humic Acid Using XDLVO Approach: Effect of Calcium Ions[J]. Environmental Science, 2012,33(6):1884-1890.

[9] Ang W S, Elimelech M. Protein (BSA) fouling of reverse osmosis membranes: implications for wastewater reclamation[J]. Journal of Membrane Science, 2007, 296:213-221.

[10] Salem A I, Okoth G, Thöming J. An approach to improve the separation of solid-liquid suspensions in inclined plate settlers: CFD simulation and experimental validation[J]. Water Research, 2011, 45: 3541-3549.

[11] Volodymyr V A, Francoise P. Morphology of deposits formed from chemically heterogeneous suspensions application to membrane filtration[J]. Journal of Colloid and Interface Science, 2002, 256: $367-377$.

[12] Choi Y H, Kweona J H, Kimb D I, et al. Evaluation of various pretreatment for particle and inorganic fouling control on performance of SWRO[J]. Desalination, 2009, 247:137-147.

[13] Ralph L, Geo S, David J, et al. Application of high speed imaging as a novel tool to study particle dynamics in tubular membrane systems[J]. Journal of Membrane Science, 2011, 368:95-99.

[14] Wang Y, Jin W, He W B. Research on in flow velocity field in jagged micro-channel based on Micro-PIV[J]. Journal of Xi'an Jiao Tong University, 2009, 43 (9):109-113.

[15] Wereley S T, Gui L, Meinhart C D. Advanced algorithms for micro-scale particle image velocimetry[J]. AIAA Journa1, 2002, (40): 1047-1055.

[16] Gómez R, Bashir R, Sarikaya A, et al. Microfluidic biochip for impedance spectroscopy of biological species[J]. Biomedical Microdevices, 2001, (3): 201-209.

[17] Patrick E, Matt P, Carl D, et al. Quantum nanospheres for sub-micron particle image velocimetry[J]. Experimental Fluids, 2007, 43:525-533.

[18] Jeffrey S G, Peter Huang, Kenneth S. Breuer. Statistical particle tracking velocimetry using molecular and quantum dot tracer particles[J]. Experimental Fluids, 2006, 41:869-880.

[19] Zhang W, Xu D Y, Zheng X Q, et al. Process simulation of fractal growth of microfiltration membrane fouling[J]. Chinese Journal of Environmental Engineering, 2012, 6(10):3509-3513.

[20] Hou P X, Cai L, Yu W P. Experimental study and fractal analysis of ice crystal structure at initial period of frost formation[J]. Journal of Application Science, 2007, 25(2): 193-197. 